\title{
Design Procedure Enhanced with Numerical Modeling to Mitigate River- Bank Erosion
}

\author{
Mohamed Elhakeem ${ }^{1}$, and Thanos Papanicolaou ${ }^{2}$ \\ ${ }^{1}$ Abu Dhabi University, Abu Dhabi, P.O. Box 59911, UAE \\ ${ }^{2}$ The University of Tennessee, Knoxville, TN, 37996, USA
}

\begin{abstract}
In this study, the 2D Finite Element Surface Water Modeling System (FESWMS) is used to design barb structures to mitigate river bank erosion in a stream reach located on the Raccoon River near Adel, Iowa, USA just upstream of the US Highway Bridge 169. FESWMS is used also to access the barbs effect on the study reach. The model results showed that the proposed barb structures successfully reduced the flow velocity along the outside bank and increased the velocity in the center of the stream, thereby successfully increased the conveyance towards the core of the river. The estimated velocities values along the river-banks where the barbs exist were within the recommended values for channel stability design. Thus, the barb structures were able to reduce the erosion along the bankline.
\end{abstract}

\section{Introduction}

Barb (either spur or bendway weir) structures have been used in many streams to mitigate streambank erosion by redirecting stream flow away from the banks towards the core of the channel [1]. Yet, detailed guidelines for barbs design are limited due to the site specificity involved in most studies [1]. Therefore, hydraulic engineers must resort to physical and/or computational models to predict the effects of barb structures on riverine environment and base their design on the model outputs. Computational models can be adapted for different physical domains more easily than physical models [2]. In addition, computational models are not subjected to distortion effects like physical models when a solution can be obtained for the same flow conditions as those present in the field (i.e., complete similarity by having the same length scale in the three directions, and identical hydrodynamic and kinetic forces). However, computational models must be calibrated and verified against laboratory or field data [2].

Numerous commercially hydrodynamic models exist for various intended applications, which can broadly be classified into 1D, 2D and 3D models [2]. 2Dhydrodynamic models have been deemed to be ideal for simulating flow in stream reaches containing barb structures because they can resolve the large-scale turbulent flow structure and provide spatially varied information regarding the flow pattern around barbs [3]. In addition, 2D models require less data than 3D models for model calibration and verification, which make them more attractive [3]. The majority of the 2Dhydrodynamic models typically solve the depth-averaged continuity and Navier-Stokes equations using finitedifference, finite-element, or finite-volume schemes [2].

In this study we used the Finite Element Surface Water Modeling System (FESWMS) to design the barb structures and access their effect on a stream reach located on the Raccoon River near Adel, Iowa, USA just upstream of the US Highway Bridge 169. FESWMS is a commercially available 2D-hydrodynamic model developed by the Federal Highway Administration [4]. The model has a proven track record in modeling riverine environment and was successfully used to simulate flow in river bends where secondary currents were prevalent, and to study bank erosion in a straight reach of a stream [5]. It was also used to study fish habitat in a gravel-bed stream under different bed-roughness conditions and to study shallow water habitat around dikes in the Missouri River [6]. Detailed sensitivity analysis and error propagation studies have shown that FESWMS provides in general satisfactory results for streams of complex geometry and bed-roughness when the model is carefully calibrated against field measurements [7].

\section{Methodology}

The methodological steps needed to accomplish the study objective include: 1) a review of the essential criteria for designing barb structures; 2) description of the study site and collection of field data for model validation; 3) description of the important features of the 2D hydrodynamic model.

\subsection{Barbs design guidelines}


The general design guidelines of barbs (e.g., length, spacing) have been documented in many hydraulics textbooks [1]. The design criteria depend mainly on the purpose of the structures (e.g., bank erosion protection vs. navigation improvement) and are based on a fundamental understanding of the prevailing flow regions in the vicinity of the barbs. The length of barbs is primarily a function of the amount of flow needed to be redirected towards the core of the channel [1]. The maximum length of a barb is determined from the maximum permissible flow depth and velocity at the main-core region [1]. Typical design specifications recommended that the barb length to stream width ratio $(\mathrm{L} / \mathrm{B})$ is less than 0.5 [1]. For $\mathrm{L} / \mathrm{B}$ values greater than 0.5 , the flow becomes increasingly contracted causing excessive bed-scour in the main-core region and back water effects. The spacing between the barbs depends upon the structure length and typical design specifications recommended that the spacing to length ratio $(\mathrm{S} / \mathrm{L})$ is between 0.75 and 2.0 [1]. The majority of the existing studies have evaluated the design criteria (other than spacing) from investigating the flow pattern around a single barb. However, multiple barbs are often used to control bank erosion in a stream reach. Introducing a series of barb structures in a stream reach can have large scale effects by increasing the total flow resistance of the reach creating backwater effects [8]. The presence of barbs affects the water surface profile and the overall spatial distribution of the velocity in the main-core and the barb regions [1]. It is therefore important to simulate the entire series of barbs to understand fully the large scale effects of these structures on the hydrologic and morphologic characteristics of a stream [8].

\subsection{Study site and field work}

The study site is located on the Raccoon River near Adel County, Iowa, USA just upstream of the US Highway Bridge 169. Figure 1a shows the study site after the construction of the barbs. The study reach has a sandy bed of mild gradient with an average bed slope of 0.00061 , and a meandering pattern with an average sinuosity of 1.8 , producing deeply entrenched corners in silt-clay banks with height exceeding $3.0 \mathrm{~m}$. The bridge causes excessive bank erosion and formation of a meander bend well-upstream of the bridge span. The observed river-bank erosion appears to be accelerating as the bridge acts as a control structure not allowing the downstream portion of the reach to adjust to changes upstream. Field measurements were performed to support the numerical simulations. The field work included detailed velocity measurements using Large Scale Particle Image Velocimetry (LSPIV) technique (Figure 1b), and collection of bathymetry data of the study reach using standard surveying practices and an Eagle FishElite ${ }^{\circledR} 480$ sonar. LSPIV is an image-based approach [9] for measuring time-averaged, water surface velocities over large areas $\left(<225 \mathrm{~m}^{2}\right)$. It provides not only the velocity magnitudes, but also the overall flow pattern. This non-intrusive method, which is based on particle tracking velocimetry can provide large data sets of simultaneously measured velocity vectors and resolve for large-scale flow patterns with errors less than $10 \%$ [9]. The velocity vectors can be determined using particle image velocity algorithms, which estimate the displacement of seeding particles through a sequence of recorded images. Eco-friendly wood mulch as the seeding material and video cameras with a resolution of $720 \times$ 480 pixels mounted on a truck are often sufficient to capture the mulch movement at the free surface. The large sample size provided by the LSPIV technique allows for a better statistically significant comparison between the measured and predicted velocity values. Bathymetry data were collected using standard surveying practices and an Eagle FishElite ${ }^{\circledR} 480$ sonar. The Eagle FishElite $\AA \quad 480$ is a coupled sonar/GPS instrument capable of recording depth and corresponding positional data at a rate of $1.0 \mathrm{~Hz}$ with errors less than $5 \%$ [10]. These measuring techniques allowed recording large samples of data to be used for computational mesh generation and model calibration and verification.

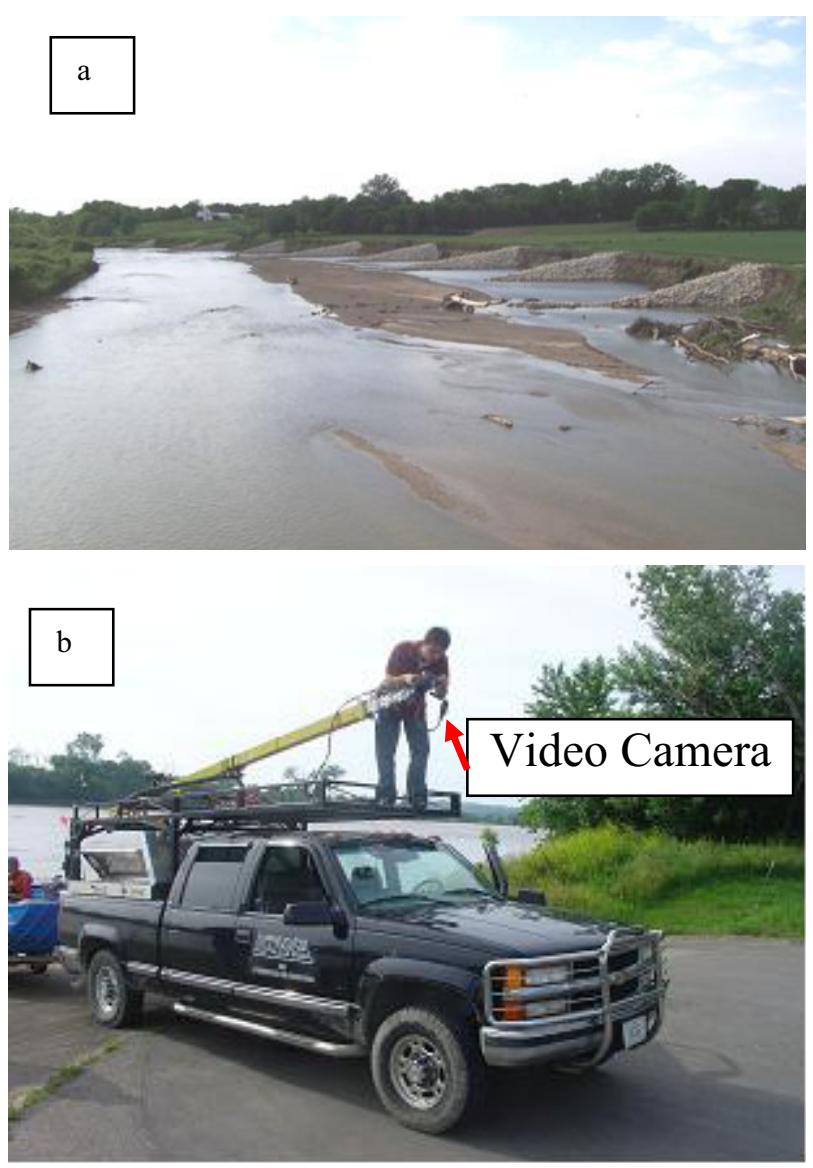

Figure 1. a) Study site after the construction of the barbs; b) the Large Scale Particle Image Velocimetry (LSPIV) technique.

\subsection{Model description and calibration}

FESWMS is part of the commercially available Surface water Modeling System (SMS) package version 10.2 Graphical Interface that combines a series of hydrodynamic/ sediment codes [4]. FESWMS solves the differential forms of the continuity and the momentum equations in the stream wise and transverse directions 
using the Galerkin method of weighted residuals, providing water depth and depth-averaged velocity magnitude in $x$ and $y$ directions at each node in the grid [4]. The governing equations are written in the conservative form hence, the momentum is conserved along the streamline and the model is capable of capturing shock effects [11]. The conservative form was chosen because of its robustness in solving critical and transcritical flow fields under both low and high flow conditions by allowing dry-elements to exist within the computational mesh [11].

FESWMS solves the following equations simultaneously:

$$
\begin{gathered}
\frac{\partial z_{w}}{\partial t}+\frac{\partial q_{1}}{\partial x}+\frac{\partial q_{2}}{\partial y}-q_{m}=0 \\
\frac{\partial q_{1}}{\partial t}+\frac{\partial}{\partial x}\left(\frac{q_{1}^{2}}{d}+\frac{1}{2} g d^{2}\right)+\frac{\partial}{\partial y}\left(\frac{q_{1} q_{2}}{d}\right)+g d \frac{d z_{b}}{\partial x} \\
+g n^{2} \frac{q_{1} \sqrt{q_{1}^{2}+q_{2}^{2}}}{d^{7 / 3}} \sqrt{1+\left(\frac{\partial z_{b}}{\partial x}\right)^{2}+\left(\frac{\partial z_{b}}{\partial y}\right)^{2}} \\
-2 d \varepsilon_{x x} \frac{\partial^{2} \bar{u}}{\partial x^{2}-\varepsilon_{x y}} \frac{\partial}{\partial y}\left(\frac{\partial \bar{u}}{\partial x}+\frac{\partial \bar{v}}{\partial y}\right)=0 \\
\frac{\partial q_{2}}{\partial t}+\frac{\partial}{\partial x}\left(\frac{q_{1} q_{2}}{d}\right)+\frac{\partial}{\partial y}\left(\frac{q_{2}^{2}}{d}+\frac{1}{2} g d^{2}\right)+g d \frac{d z_{b}}{\partial y} \\
+g n^{2} \frac{q_{2} \sqrt{q_{1}^{2}+q_{2}^{2}}}{d^{7 / 3}} \sqrt{1+\left(\frac{\partial z_{b}}{\partial x}\right)^{2}+\left(\frac{\partial z_{b}}{\partial y}\right)^{2}} \\
-2 d \varepsilon_{y y} \frac{\partial^{2} \bar{v}}{\partial y^{2}}-\varepsilon_{y x} \frac{\partial}{\partial x}\left(\frac{\partial \bar{u}}{\partial x}+\frac{\partial \bar{v}}{\partial y}\right)=0
\end{gathered}
$$

where (1) is the continuity and (2) and (3) are the momentum equations in $x$ and $y$ directions, respectively. In the equations, $t$ is time (s), $d$ is water depth (m), $\rho$ is water density $\left(\mathrm{kg} / \mathrm{m}^{3}\right), g$ is the acceleration due to gravity $\left(\mathrm{m} / \mathrm{s}^{2}\right), n$ is Manning's coefficient of roughness, $z_{w}$ and $z_{b}$ are water surface elevation and bed elevation above certain datum (m), $q_{1}$ and $q_{2}$ are the unit discharge fluxes $\left(\mathrm{m}^{2} / \mathrm{s}\right)$ defined as $\bar{u}_{d}$ and $\bar{v}_{d}$, respectively, $\bar{u}$ and $\bar{v}$ $(\mathrm{m} / \mathrm{s})$ are the depth-averaged velocities of an element in the stream wise and transverse directions, respectively, $q_{\mathrm{m}}$ is the resultant inflow or outflow from that element $(\mathrm{m} / \mathrm{s}), v_{x x}$ and $v_{y y}$ are the normal components of the eddy viscosity $\left(\mathrm{m}^{2} / \mathrm{s}\right)$ in the $x$ and $y$ directions, respectively, and $v_{x y}$ and $v_{y x}$ are the shear components of the eddy viscosity $\left(\mathrm{m}^{2} / \mathrm{s}\right)$ applied to the $x-y$ plane.

FESWMS inputs for model calibration are the Manning's coefficient of roughness $n$, and the eddy viscosity $v$. Model inputs must be assigned correctly to represent the physical processes occurring in the modeled reach and to produce accurate model predictions. Manning's $n$ is an empirical coefficient that accounts for the total flow resistance caused by flow interaction with the boundary [12]. FESWMS utilizes Manning's $n$ to account for momentum loss due to bed-shear, which may vary significantly in a stream reach in accordance to bedbathymetry and roughness. The second input variable used by FESWMS is the eddy viscosity $v$. Eddy viscosity accounts for flow resistance due to the internal shear stresses, or the Reynolds' stresses of the fluid incorporating the added energy dissipation due to turbulence in the flow [13]. Therefore, eddy viscosity is not a physical property of the fluid, but rather a turbulent characteristic of the flow. Because of the complex geometry of the study reach, distributed Manning's $n$ and eddy viscosity values are used for model calibration (Figure 2).

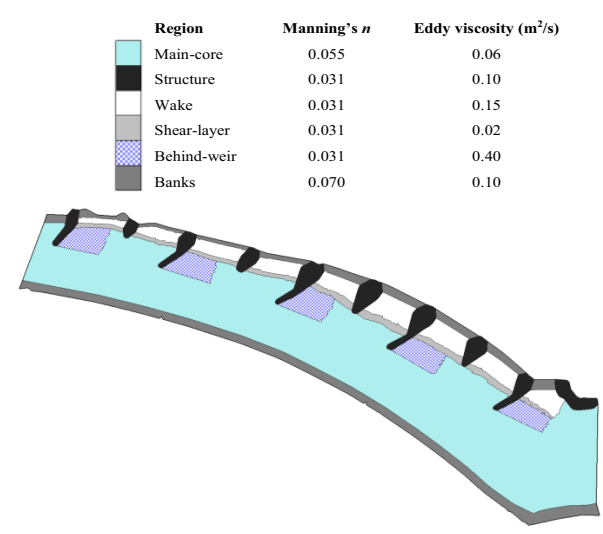

Figure 2. Spatially distributed Manning's $n$ and eddy viscosity values over the study reach.

\section{Results}

\subsection{Barbs design}

Barbs (spurs and bendway weirs) were proposed for river-bank protection (Figure 3). The average length to width ratio $(\mathrm{L} / \mathrm{B})$ and average spacing to length ratio $(\mathrm{S} / \mathrm{L})$ of the structures are $1: 3$ and $2: 1$, respectively. Spurs was proposed to protect the bank line and force the river to the north, and bendway weirs to further redirect the flow from the backline towards the channel core. The major advantage of this system is correction of the incoming flow. The average length of the spurs and bendway weirs were $16 \mathrm{~m}$ and $32 \mathrm{~m}$, respectively, with a top width of 2.5 $\mathrm{m}$ and side slope of $2: 1$. The spurs are perpendicular to the flow field, whereas the weirs have an angle of $65^{\circ}$ with the flow field. The design is based on that the noses of the spurs were located above the streambed for most of the time during the year, and rise with a slope of $6: 1$, until they meet the bank elevation. However, the crests of the weirs extend horizontally from the elevation of the spurs noses toward the river centerline. Spurs noses and weirs crests were set at elevation 255.5, which corresponds to 2 year return period of the water flow depth. This elevation corresponds to $0.75 \mathrm{~m}$ above the streambed and discharge of $26 \mathrm{~m}^{3} / \mathrm{s}$. Top of the spur was set at constant elevation of 265.3, which corresponds to the bank-full condition. This elevation corresponds to $4.3 \mathrm{~m}$ above the streambed 
and discharge of $312 \mathrm{~m}^{3} / \mathrm{s}$. The size of the barb structures is based on the 100-year flood of the stream, which is 430 $\mathrm{m}^{3} / \mathrm{s}$.

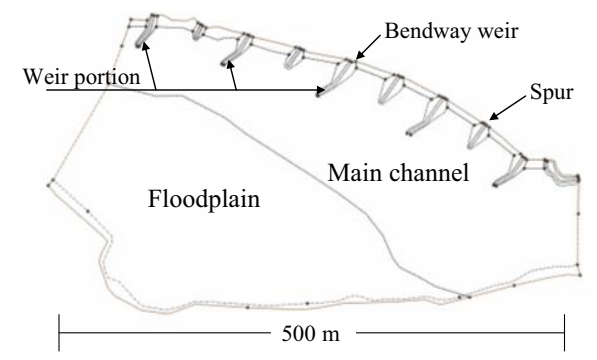

Figure 3. Plan view of the spurs and bendway weir arrangement.

\subsection{Performance evaluation}

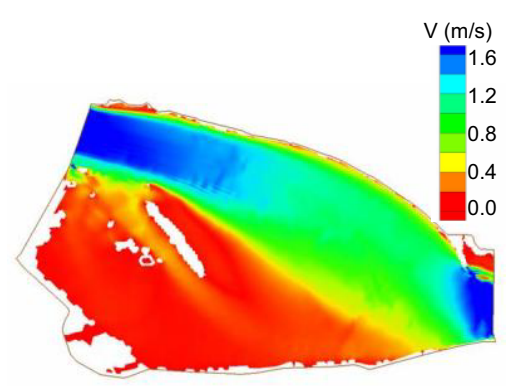

Figure 4. Flow condition with no barbs (velocity distribution).

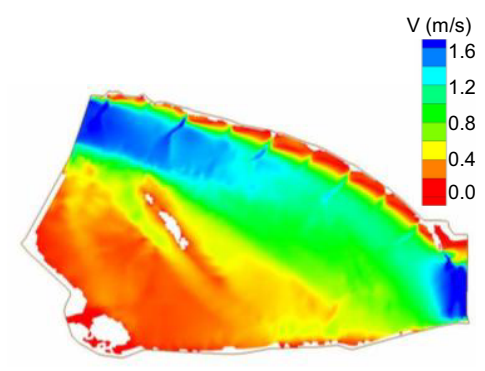

Figure 5. Flow condition with optimal number of barbs (velocity distribution).

The hydrodynamic model FESWMS was used to obtain the optimal number, location, and spacing between the barbs. The model inputs are: the stream bathymetry, values of Manning's coefficient $n$ and eddy viscosity $v$ shown in Figure 2, flow rate at the upstream section $Q=$ $312 \mathrm{~m}^{3} / \mathrm{s}$, and water depth at the downstream section $y=$ $4.3 \mathrm{~m}$. The bank-full flow condition $\left(Q=312 \mathrm{~m}^{3} / \mathrm{s} ; y=\right.$ $4.3 \mathrm{~m}$ ) was used to evaluate the overall performance of the barbs (spurs and bendway weirs) in controlling bank erosion. In performing the numerical simulations, the model was run with and without the barbs present. The flow condition in the case of no-barbs (Figure 4) was used as reference for comparison and to evaluate the barbs effect on the stream reach. The first simulation (not shown here) started with the 15 barbs ( 7 spurs and 8 bendway weirs) distributed equally over the study reach. If this barbs arrangement alters the flow condition by increasing the flow velocities on the opposite bank (compared with the no barb condition), the number of barbs in the next run is reduced until the barbs effect on the opposite river-bank has minimal on the flow condition. The model simulations (Figure 5) showed that the optimal number of barbs are 9 (4 spurs and 5 bendway weirs) with a spacing of 45-50 $\mathrm{m}$ between them (Figure 3). As can be seen from Figure 5 the barbs reduced the velocity dramatically near the north bank.

\section{Summary}

The 2D Finite Element Surface Water Modeling System (FESWMS) is used in this study to design the barb structures to mitigate river-bank erosion in a stream reach located on the Raccoon River near Adel, Iowa, USA just upstream of the US Highway Bridge 169. FESWMS results showed that the proposed barb structures successfully reduced the flow velocity along the outside bank and increased the velocity towards the center of the stream, thereby successfully increased the conveyance in the core of the river. The estimated velocities along the banks of the river where the barb structures exist were within the recommended values for channel stability design (velocity $=0.5 \mathrm{~m} / \mathrm{s}$ ). Thus, the barb structures were able to reduce the erosion along the bankline.

\section{References}

1. B. Przedwojski, R. Blazejewski, and K.W. Pilarczyk, River Training Techniques, A.A. Balkema: Rotterdam, Brookfield, Vt., (1995)

2. A.N. Papanicolaou, M. Elhakeem, G. Krallis, S. Prakash, and J. Edinger, J. Hydraul. Eng., 134, 1 (2008)

3. M. Spasojevic, and F.M. Holly, Proc. 4th Inter. Conf. Hydroinformatics, The University of Iowa, Iowa, (2000)

4. D. Froelich, User's Manual for FESWMS Flo2DH: Two-Dimensional Depth-Averaged Flow and Sediment Transport Model, Release 3, (2002)

5. A.Z. Khan, and B. Barkdoll, Int. J. Comput. Eng. Sci., 2, 3 (2001)

6. A.N. Papanicolaou, M. Elhakeem, D. Dermisis, and N. Young, River Research and Applications, (2010)

7. G.B. Pasternack, A.T. Gilbert, J.M. Wheaton, and E.M. Buckland, J. Hydrol., 328, 1-2 (2006)

8. H. Azinfar, and J.A. Kells, J. Hydraul. Eng., 134, 8 (2008)

9. J.D. Cruetin, M. Muste, A.A. Bradley, S.C. Kim, A. and Kruger, J. Hydrol., 277, (2003)

10. T.D. Osting, CRWR Online Report 04-01, Center for Research in Water Resources, University of Texas, Austin, TX, (2004)

11. H.M. Chaudhry, Open Channel Flow, Springer, New York, (2008)

12. D.M. Hicks, P.D. Mason, Roughness Characteristics of New Zealand Rivers, New Zealand DSIR Marine and Freshwater Resources Survey, Wellington, NZ, (1991)

13. A.N. Papanicolaou, R. Hilldale, J. Eng. Mech., 128, 9 948-960 (2002) 